\title{
Online Requirements and Portal Design for Female University Science and Technology Students in Kenya ${ }^{*}$
}

\author{
Stephen Kimani, Eunice Njeri, and John Njue \\ Institute of Computer Science, Jomo Kenyatta University (JKUAT), \\ P.O. Box 62000 - 00200 Nairobi, Kenya \\ \{stephenkimani,njeri.eunice, njuejohn\}@gmail.com
}

\begin{abstract}
In science and technology (S\&T) career progression, women drop out at virtually every step until extremely few are found in positions of influence and recognition. Although this is a global problem, it is even more critical in Africa. The number of female university S\&T students in Africa has remained low for the past about three decades. There is thus a dire need to encourage/support such students especially in African countries, including Kenya. Online portals have the potential to motivate/support Kenyan female university S\&T students. It is however critical to understand the characteristics and requirements of these students. While there exists literature on the differences between online female users and male users, women in S\&T in African countries (including Kenya) face rather unique challenges. This paper reports a study that indicates the characteristics and online requirements of Kenyan female university S\&T students, and then describes a corresponding online portal design.
\end{abstract}

Keywords: Online user requirements, user interface design, online portals, science and technology, female students.

\section{Introduction}

In science and technology (S\&T) career progression, women drop out at virtually every step until extremely few are found in positions of influence and recognition. Although this is a global problem, it is even more critical in Africa [1]. Kabeer and Magnus [1] go on to say that in Africa unlike other regions of the world, the number of women pursuing S\&T studies at university has remained low and stagnated for the past about three decades. According to Karanja in [2], the relatively lower number of S\&T female students in Kenyan universities is attributed to factors such as: gender stereotyping; early pregnancies, heavier domestic workloads, etc. There is thus a dire need to encourage and support women who are pursuing S\&T in universities especially in African countries, including Kenya.

Research funded by Strengthening Information Society Research Capacity Alliance, SIRCA II. 
On the same note, research suggests that Internet-based interventions, such as online portals, can lead to positive changes in motivation, perception and behavior (e.g. [3], [4]). Online portals therefore have the potential to motivate and support Kenyan female university S\&T students. One of the key prerequisites to designing appropriate online portals for Kenyan female university S\&T students is to gain a deeper understanding of: their background, the challenges they face, their rating of potential interventions to the challenges, their Internet access and usage, their experience with and preferences for online portals. Various studies have been conducted in order to understand systematic differences between online female users and their male counterparts (e.g. [5], [6], [7]). While it is possible to glean from such studies the characteristics and requirements of online female users, it is however worth reiterating that women in S\&T in African countries (including Kenya) face challenges that are rather unique from those faced by women in other parts of the world [1][2].

There exist a number of females and technology websites (e.g., wigsat.org, awis.org, etc), but they do not take into account the unique contextual challenges and specific needs of female university S\&T students from Kenya. It should also be noted that gender-disaggregated data pertaining to women in S\&T in Kenya is largely unavailable [8]. There is therefore the need to conduct a study that illuminates our understanding of the characteristics, needs, and online requirements of Kenyan women in S\&T. This research work in particular characterizes Kenyan female university S\&T students, describes their online portal requirements, and presents a corresponding online portal design. The contribution of this paper is therefore two-fold:

- It describes the specific online user requirements of Kenyan female university S\&T students.

- It proposes and describes an online portal user interface design appropriate for Kenyan female university S\&T students.

The rest of the paper is organized as follows: Section 2 describes the online requirements study in terms of the methodology, findings and emanating requirements; Section 3 describes the realized portal design; and Section 4 concludes the paper.

\section{Online Usage and Requirements Study}

This describes the study methodology, findings and emanating requirements.

\subsection{Methodology}

The study was aimed at determining online usage and requirements of Kenyan female university S\&T students. We designed and administered a questionnaire targeting female university S\&T students in Kenya. The questionnaire had questions on: 
- Demographics of Kenyan female university S\&T students

- Barriers and interventions related to Kenyan female university S\&T students

- Internet access and usage of Kenyan female university S\&T students

- Services and features that are desirable in online portals for Kenyan female university S\&T students

The questions/items included in the questionnaire were informed by literature review on relevance of ICT in empowering women and promoting gender equality (such as [9][10]), common services/features in existing S\&T portals, and also by preliminary interviews we had previously conducted with successful women in S\&T in Kenya. Participants were recruited using: direct emailing, snowballing sampling, and class mailing lists. The questionnaire was made available online and in hardcopy. It was sent to 104 Kenyan female university S\&T students. It was administered August-October 2012. Out of the 104 students contacted, 35 completed the questionnaire.

\subsection{Findings and User Requirements}

This subsection reports the findings and the emanating user requirements.

Demographics and Gender-Related Issues. Most of the respondents (86\%) were undergraduate students. Female university students in S\&T highlighted many challenges that they have personally faced as females students in S\&T. The most highlighted challenge was financial constraints. The female university students also highlighted challenges that they know other female S\&T students have faced. The most cited challenge was again financial constraints. From both the challenges that the students personally faced and the challenges they knew others faced, the top challenges were: Financial constraints, Stereotypes related to women, Lack of mentoring, Academic programme is sometimes not relevant to the real-world, Lack of exposure, Lack of networks, Isolation/male-dominated environment, Discrimination, Lack of recognition, Family didn't have confidence in them, Lack of assertiveness. The highlighted challenges echo what Kabeer and Magnus in [1] have highlighted as Africa-specific gender-related obstacles and what other researchers have highlighted as Kenya-specific gender-related obstacles. For instance: lack of access to good quality S\&T education for females [1] (an obstacle related to Lack of exposure); failure of the formal S\&T education to demonstrate the relevance of S\&T to the females' day-to-day lives and challenges [1][11] (an obstacle related to Academic programme is sometimes not relevant to the real-world); and sociocultural obstacles such as: gender stereotyping and customs, heavier domestic workloads for daughters than sons, etc [2] (obstacles related to Stereotypes related to women and discrimination).

As for the female S\&T students' rating of interventions for addressing the challenges women in S\&T face, the percentages can be seen in Fig. 1. 


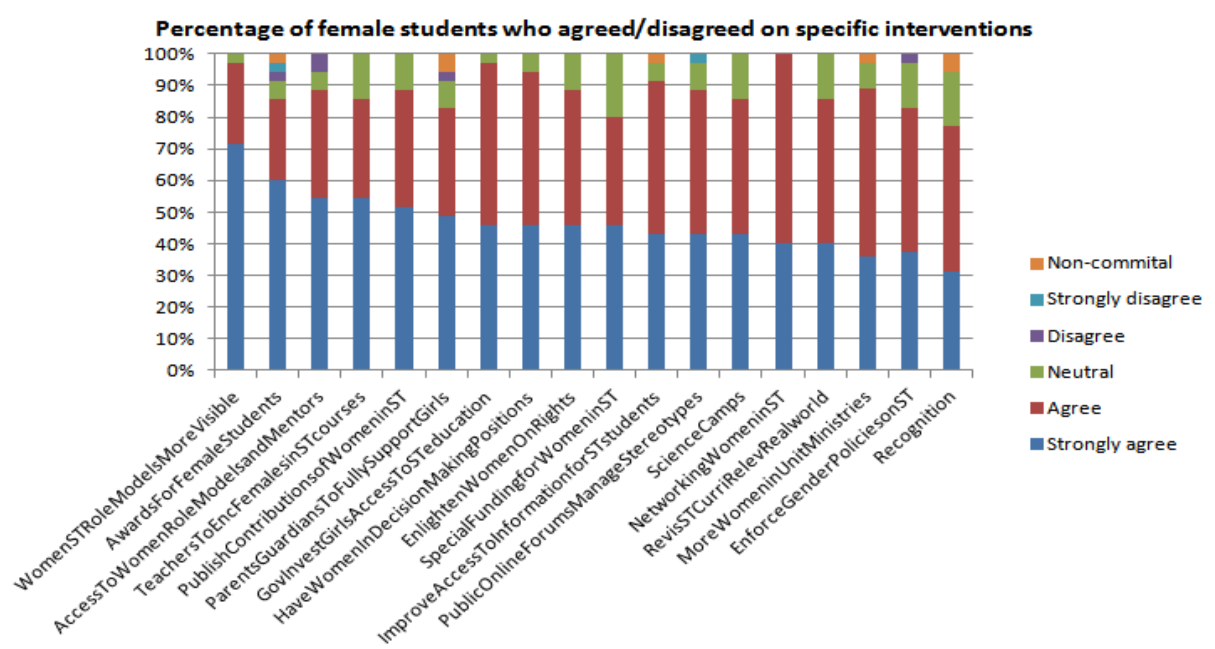

Fig. 1. Interventions for addressing the challenges

Internet Access and Usage. The main Internet access methods in and outside the university were: wireless connectivity, Internet access through a personal airtime modem on laptop or computer, Directly from mobile phone, Internet café. Most of the female S\&T students reported a high frequency of their overall Internet usage (i.e. $71 \%$ use Internet several times a day). Most of the female S\&T students use the Internet to Send and receive emails. More information can be seen in Fig. 2.

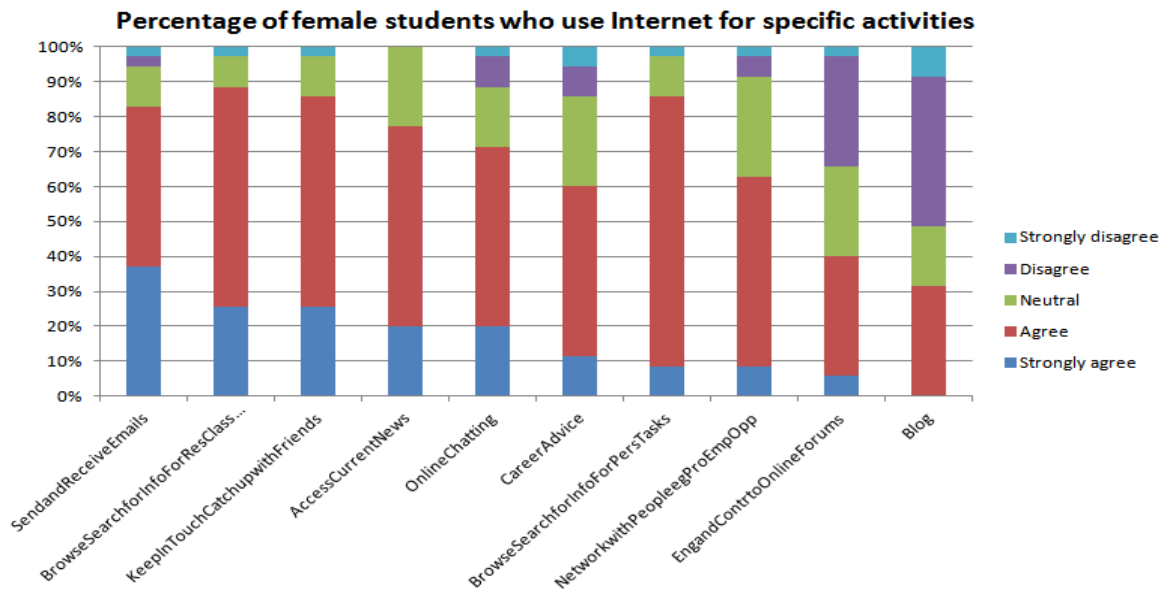

Fig. 2. Specific Internet activities

The female S\&T students reported on the importance of specific Internet activities as seen in Fig. 3. Browse and search for information for their research and class work was leading and closely followed by Send and receive emails. It is worth mentioning that the Internet activities that female S\&T students perform largely correspond to 


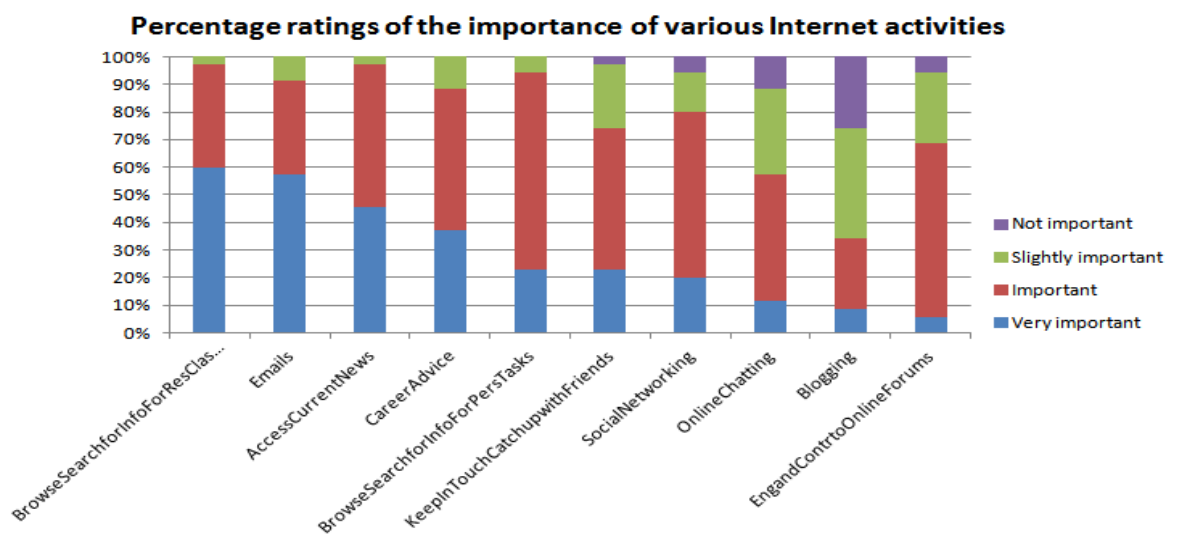

Fig. 3. Importance of specific Internet activities

those that they consider of high importance. For instance: Email, Browse and search for information for research/class work, Access current news, Keep in touch/catch up with friends, Career advice, Browse and search for information for personal tasks.

Online Portal Services and Features. The female S\&T students also reported on the importance of specific services and features if they were to be included in portals for female university students in S\&T as seen in Fig. 4. We give a summarized description of the services/features that were rated as the most important in Table 1.

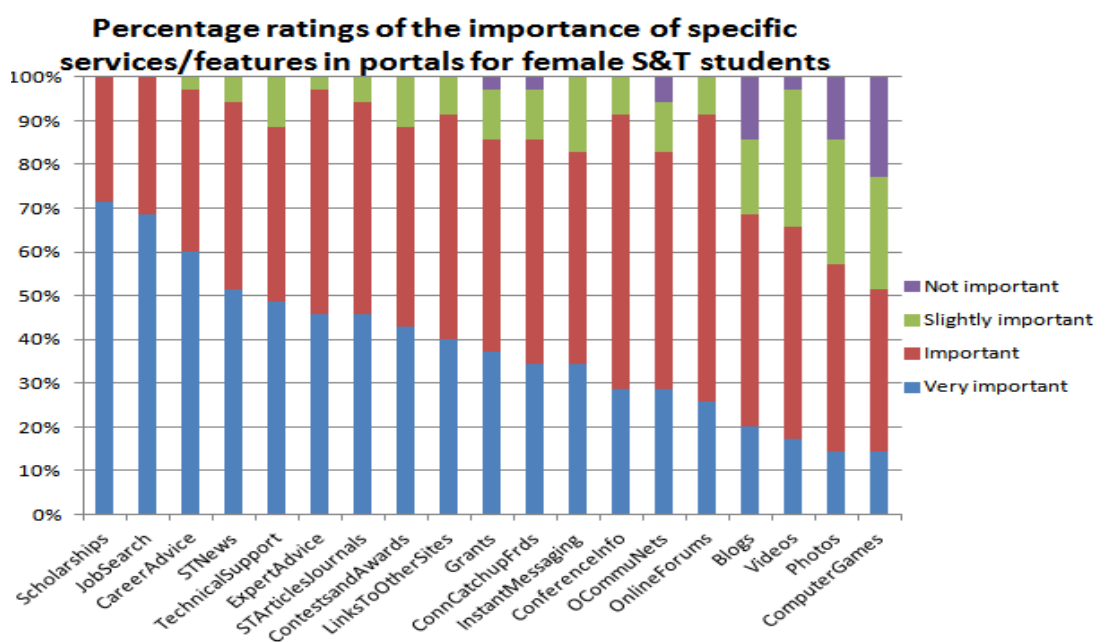

Fig. 4. Importance of services/features in future portals for female S\&T students

Summary of the Findings and User Requirements. There were various specific portal services and features that were rated as important by respondents. The proposed portal should particularly seek to support the following services and features: Scholarships, Job search, Email support, Career advice, S\&T news, Technical support, 
Table 1. Most important services/features

\begin{tabular}{|c|c|}
\hline Service/feature & Relationship with other findings \\
\hline Scholarships & $\begin{array}{l}\text { Financial constraints were earlier on highlighted as the challenge most of the female } \\
\text { S\&T students had faced, and knew other female S\&T students who had faced it. }\end{array}$ \\
\hline Job search & $\begin{array}{l}\text { This is closely related with Career advice, which was also rated as an Internet activi- } \\
\text { ty of relatively high importance as a general Internet activity. }\end{array}$ \\
\hline Career advice & $\begin{array}{l}\text { As noted in the row above, this was also rated as an Internet activity of relatively } \\
\text { high importance as a general Internet activity. It is also worth noting that this could } \\
\text { be due to lack of mentoring, lack of exposure and lack of networks, which were pre- } \\
\text { viously highlighted as some of the top challenges that female S\&T students face. }\end{array}$ \\
\hline S\&T news & This too had been rated as one of the most important general Internet activities. \\
\hline Technical support & - \\
\hline Expert advice & $\begin{array}{l}\text { This could be due to lack of exposure and lack of networks, which were earlier hig- } \\
\text { hlighted as some of the top challenges that female S\&T students face. }\end{array}$ \\
\hline $\begin{array}{l}\text { S\&T articles and } \\
\text { journals }\end{array}$ & $\begin{array}{l}\text { It was earlier on reported that Publishing the contributions of women in } S \& T \text { was one } \\
\text { of the top interventions that the female } S \& T \text { students had proposed. }\end{array}$ \\
\hline $\begin{array}{l}\text { Contests and } \\
\text { awards }\end{array}$ & $\begin{array}{l}\text { This could be due to lack of recognition, which was earlier on reported as one of the } \\
\text { top challenges female } \mathrm{S} \& \mathrm{~T} \text { students face. It was earlier on also reported that Awards } \\
\text { for female students was one of the top interventions these students had proposed. }\end{array}$ \\
\hline Links to other sites & - \\
\hline Grants & Financial constraints had been rated as the female S\&T students' topmost challenge. \\
\hline $\begin{array}{l}\text { Connecting and } \\
\text { catching up with } \\
\text { friends }\end{array}$ & $\begin{array}{l}\text { This was also rated as an Internet activity of relatively high importance as a general } \\
\text { Internet activity. Moreover, lack of networks was earlier on reported as one of the top } \\
\text { challenges female S\&T students face. }\end{array}$ \\
\hline Instant messaging & This is related to lack of networks, one of the female S\&T students' top challenges. \\
\hline
\end{tabular}

Expert advice, S\&T articles and journals, Contests and awards, Links to other sites (e.g. library catalogs), Grants, Connecting and catching up with friends, and Instant messaging. The proposed portal should also have services and features for addressing the main challenges that female S\&T students face. Moreover, the proposed portal should have services and features for supporting the outstanding interventions for addressing challenges that women in S\&T face. For instance: information about financial/funding opportunities; online discussion forums where female S\&T students can manage discuss and educate one another on stereotypes; providing the correct or accurate information about women; information about female role models or successful women in $S \& T$; enable female S\&T students to interact with mentors; etc.

\section{$3 \quad$ StoreRooms User Interface Design}

In this section, we describe the preliminary user interface design of an online portal for Kenyan female university S\&T students based on the findings of our study. The online portal is referred to as StoreRooms ( Science and Technology Opportunities and Resources Portal for Kenyan Female University Students). The primary target users of the online portal are Kenyan female university S\&T students. Toward ensuring that the proposed online portal addresses the requirements emanating from Section 2, the services/features are categorized/structured as seen in Fig. 5. Under each item in that level, we have the corresponding sub-items (e.g. Fig. 6 for sub-item Opportunities). 


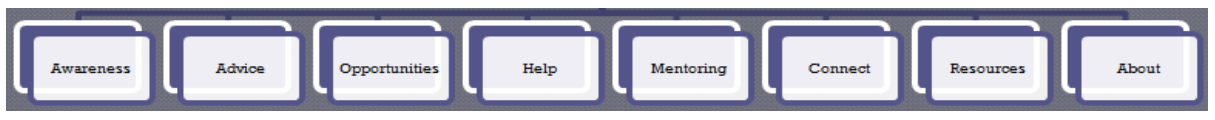

Fig. 5. Categorization and structure (high level layer)

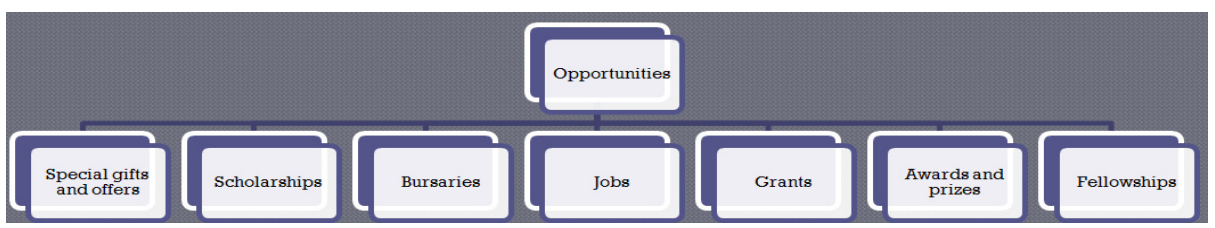

Fig. 6. Sub-items for menu item Opportunities

We have realized the preliminary user interface design based on the foregoing service and feature categorization/structuring. The corresponding design for the high level items is as seen in Fig. 7. An example of the design of the user interface for lower level layers can be seen in Fig. 8 (for Scholarships under sub-item Opportunities). Note in the lower level layers of the user interface, there is a home menu item to take the user back to the high level.

\section{Kenyan Women in Science and Technology. United We can help a sister. L Login Register}

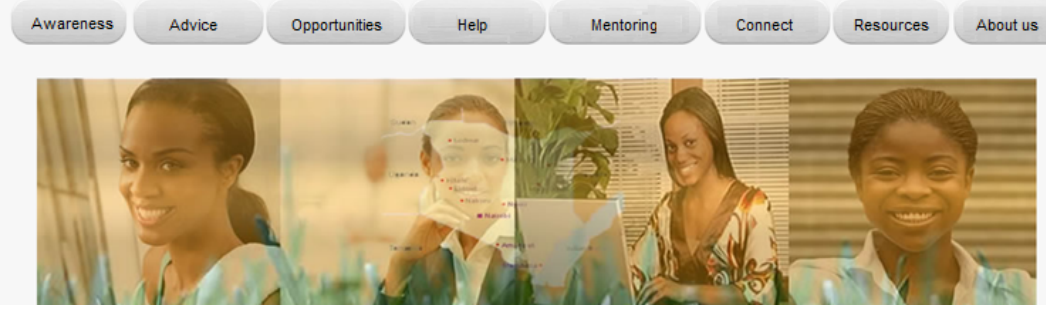

Fig. 7. Preliminary user interface design (high level layer)

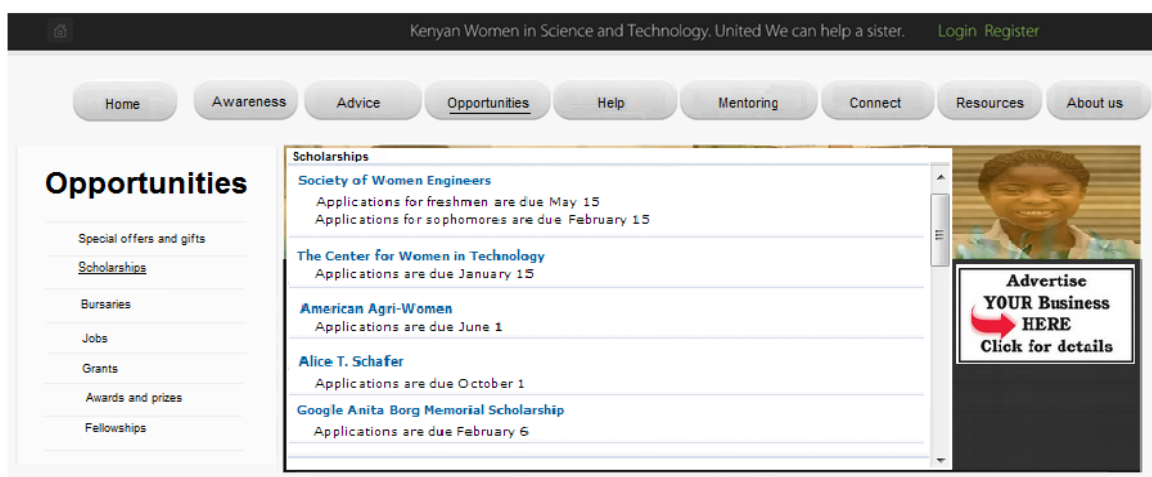

Fig. 8. Preliminary user interface design (Opportunities $>$ Scholarships) 


\section{Conclusions and Future Work}

In this paper we have described a study that was carried out in order to gain a deeper understanding of the characteristics and online requirements of Kenyan female university S\&T students with regard to online portals. We have also described the emanating user requirements and the preliminary user interface design for an online portal intended for the Kenyan female university S\&T students.

We noted in Sections 2 and 3 that the portal needs to have a service for supporting interaction between students and mentors. Based on that, we have consequently recently conducted a study involving potential mentors of Kenyan female university S\&T students. We are analyzing the data collected from the potential mentors. The online portal is being developed using user-centered design. The current preliminary design will be subjected to heuristic evaluation. The results of the evaluation and the study with the potential mentors will be used to inform subsequent refinements of the design in order to realize an improved user interface design. After that we will conduct a user-based evaluation. Besides assessing the design, the user-based evaluation will investigate user access privileges and roles, and also determine strategies for user attraction and retention.

The main Internet access methods for the female S\&T students suggest that these students rely largely on laptops and mobile devices for Internet access/use. It would thus be recommended to also consider developing a mobile version of the portal.

\section{References}

1. Kabeer, N., Magnus, E.: Building Women's Capacity in Science and Technology in the South - A Study for the Millennium Science Initiative/Science Institutes Group (2004)

2. Karanja, D.: Kenyan women hit out at male hold on science. SciDevNet website (2002)

3. Baghaei, N., Kimani, S., Freyne, J., Brindal, E., Berkovsky, S., Smith, G.: Engaging Families in Lifestyle Changes through Social Networking. International Journal of Human Computer Interaction 27(10) (2011)

4. Liebeskind, J.P., Oliver, A.L., Zucker, L., Brewer, M.: Social Networks, Learning, and Flexibility: Sourcing Scientific Knowledge in New Biotechnology Firms. Organization Science 7(4) (1996)

5. Odell, P.M., Korgen, K.O., Schumacher, P., Delucchi, M.: CyberPsychology \& Behavior 3(5), 855-862 (2000)

6. Komathi, M., Ismail, M.: Influence of gender role on internet usage pattern at home among academicians. Journal of International Social Research 2(9), 308-318 (2009)

7. Joinson, A.N.: 'Looking at', 'Looking up' or 'Keeping up with' people? Motives and uses of Facebook. In: Proc. of CHI 2008, pp. 1027-1036. ACM Press (2008)

8. MoHEST: Gender Workplace Policy. Ministry of Higher Education Science and Technology. Republic of Kenya (2009)

9. Ramilo, C., Hafkin, N., Jorge, S.: Gender Equality and Empowerment of Women through ICT. Women2000 and Beyond. United Nations (2005)

10. Narayanaswamy, L., Sever, C.: Gender and ICTs. INBRIEF Bulletin 15 (2004)

11. Chetcuti, D.A., Kioko, B.: Girls' Attitudes Towards Science in Kenya. International Journal of Science Education 34(10), 1571-1589 (2012) 